IRA-International Journal of Education \&

Multidisciplinary Studies

QUARTERLY

ISSN 2455-2526; Vol.17, Issue 01 (Jan.-March, 2021)

Pg. no. 1-7.

Institute of Research Advances

https://research-advances.org/index.php/IJEMS

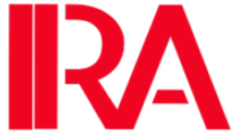

\title{
Research on English Teachers' Training of Primary and Secondary School in Villages-Based on the National Training Program
}

\section{Wang Juan}

School of Foreign Language, Yangtze University, Jingzhou, Hubei, P. R. China.

Type of Work: Peer-Reviewed

DOl: http://dx.doi.org/10.21013/jems.v17.n1.p1

How to cite this paper:

Juan, W. (2021). Research on English Teachers' Training of Primary and Secondary School in Villages-Based on the National Training Program. IRA International Journal of Education and Multidisciplinary Studies (ISSN 2455-2526), 17(1), 1-7. DOI: http://dx.doi.org/10.21013/jems.v17.n1.p1

(C) Institute of Research Advances.

This work is licensed under a Creative Commons Attribution-NonCommercial 4.0 International License subject to a proper citation to the publication source of the work.

Disclaimer: The scholarly papers as reviewed and published by the Institute of Research Advances (IRA) are the views and opinions of their respective authors and are not the views or opinions of the IRA. The IRA disclaims of any harm or loss caused due to the published content to any party.

Institute of Research Advances is an institutional publisher member of Publishers International Linking Association Inc. (PILA-CrossRef), USA. The institute is an institutional signatory to the Budapest Open Access Initiative, Hungary advocating the open-access of scientific and scholarly knowledge. The Institute is a registered content provider under Open Access Initiative Protocol for Metadata Harvesting (OAI-PMH).

The journal is indexed \& included in WorldCat Discovery Service (USA), CrossRef Metadata Search (USA), WorldCat (USA), OCLC (USA), Open J-Gate (India), EZB (Germany) Scilit (Switzerland), Airiti (China), Bielefeld Academic Search Engine (BASE) of Bielefeld University, Germany, PKP Index of Simon Fraser University, Canada. 


\begin{abstract}
The aim of the "National Training Program for Primary and Secondary School Teachers" is to promote the balanced development of compulsory education and the reform of basic education. But according to the training status of our school, I find that there are lots of significant problems directly influencing training targets during the implementation of the program. Therefore, in my opinion, to put this program into effect better and actualize the pragmaticality of teachers' training, we need to improve training modes and enhance the relevance and pragamaticality of the training content. The key solution of this program is taking teachers' training as a continuous and organic procession. Only through this way can we gradually enhance the comprehensive qualities of in-service teachers.
\end{abstract}

Keywords: National Training Program; trainee teachers; post-internship.

\title{
1. Research Background
}

According to the survey of 13 countries and cities under Jingzhou's jurisdiction in August 2019, it is reported that English teachers in the primary and secondary school of the whole rural areas in Jingzhou had existed the following phenomenons-There is an imbalance in teachers' male-to-female ration, and teachers are more likely to be younger and have structural faults; teachers may work in wrong positions and their positions structure is not reasonable; they acquire a lower first degree and their professional knowledge different from each other. Fewer teachers are English majors; they have poor teaching methodologies and professional skills; they strongly need diverse training.

Since the reform and opening up, China has paid much attention to the development of teacher's education. Although the construction of rural teachers received higher attention, the development of comprehensive qualities of rural teachers can't reach out the need for compulsory education for its balanced development. The problems of lack of qualified teachers in rural areas need to be solved immediately. Therefore, the best solution to this problem is to have large-scale training for our teachers. The 17th National Congress of the CPC put forward an idea of enhancing the construction of teacher status, especially developing the qualities of rural teachers. And then CPC made the National Outline for Medium - and Long-Term Educational Reform and Development, which is the key point of enhancing the overall qualities of teachers of primary and secondary schools, especially for rural areas.

Basing on this document and its spirits, the Ministry of Education and the Ministry of Finance worked together to launch the National Training Program for Primary and Secondary School Teachers, also known as the National Training Program. It was held by the Ministry of Education and the Ministry of Finance and put into effect in 2010. This program does great importance to enhance the comprehensive qualities and abilities of rural primary and secondary teachers, guarantee the balanced development of elementary education and develop the quality of rural education. 


\section{Implementation status of "The National Cultivation Plan"}

According to the training practice of our school in recent years, some phenomena, such as the grass-roots education administrative departments or schools do not pay enough attention to and do not have high enthusiasm, have a significant impact on the realization of the training objectives in the actual implementation of "The National Cultivation Plan".

\section{1) Trainee teachers}

At the beginning of the two sessions of "The National Cultivation Plan", the author took part in the test of their pronunciation, intonation, and oral English level. Through the tests, interviews, and follow-up investigations, it is found that there are two common situations among the trained teachers.

Firstly, the teachers who participate in the training are not professional in the major. According to the requirements of the document, the teachers participating in the training must be core teachers of English. However, the author finds that quite a few English teachers who attend the training are neither English majors nor full-time English teachers, and English teaching is only a part-time course "according to the school arrangement". Moreover, this phenomenon is common among primary school English teachers. A PE major who graduated as a primary school English teacher was unable to read the rising and falling tones of 26 English letters in an oral test, let alone any other phonetic symbols. If such a teacher is chosen to attend the training, can he play a leading role in the demonstration when he goes back to school?

Secondly, the intrinsic motivation of training teachers is insufficient. Most of the teachers in training said that they participated in the training due to external factors such as the requirements of school leaders or the need to evaluate and hire professional titles. There are very few trainees to improve their teaching ability and self-improvement. Only a few young teachers with English majors who teach in schools in the county may have expressed this idea. It can be seen that for most teachers, training is a "task assigned by leaders". This is called "want me to train," not "I want to train," and it is not the drive for internal self-improvement. Due to the above two reasons, the motivation and desire of the trainee teachers are not high. Some teachers went home after registration for various reasons, and the training time and content are greatly reduced. The professional mismatch made the training contents seem like a book to some students.

\section{2) Training Content}

As the only comprehensive university in Jingzhou, Yangtze University actively undertakes the responsibility of training teachers in primary and middle schools, but there is no specialized teacher training institution itself. Therefore, the trainers for each teacher training are mostly hired temporarily. Although most of them are professional teaching experts in the universities, the formation of the trainer team is temporary and the experts in each group are inconsistent. It is inevitable that the benevolent say benevolence and the wise say wisdom in the content of teaching. The inevitable result of this is that the training content will be lack of continuity and 
systematicness. Even though the organizers try to arrange the lecture content in advance, sometimes it is difficult to avoid problems such as the repetition of training content. The effectiveness of training will be affected greatly if the training is not a continuous and gradual process of improvement.

\section{3) Training Mode}

The "Opinions of the Ministry of Education on Vigorously Promoting the Work of Supporting Teacher Training for Normal Students" puts forward the requirements: Under their local conditions, normal colleges and universities should organize senior normal students to carry out education internships for no less than one semester in primary and secondary schools. All localities should closely integrate the internship support of normal students with the strengthening of the construction of the rural teaching team, create favorable conditions according to their actual needs, and actively arrange and accept normal students from higher normal colleges to carry out internship support in rural schools. Local education administrative departments at all levels, normal colleges and universities, and primary and secondary schools should continue to innovate the approaches and methods of teaching internships for normal students, and actively explore an effective mechanism for tripartite cooperation and collaboration to carry out educational internships for normal students.

The replacement and off-job training of the rural primary and secondary school teachers is one of the main contents of the "Central and Western Rural Backbone Teacher Training Program". The concrete implementation is to send senior normal students from normal colleges and universities to the rural primary and secondary schools where the trainees are dispatched to be trained in the colleges and universities. This measure has realized significant cooperation between universities and primary and secondary schools and has greatly promoted the pre-service and post-service training of teachers and the professionalization of teachers. However, as a new mode of teacher training, the replacement and off-job training is still being explored, and there are still many problems and shortcomings, so it will take a long time before it becomes a mainstream training mode. For example, the teachers selected by schools and education departments to participate in the training are usually the backbone teachers, but the "teachers" who replace them are all senior students who have not graduated yet. Although they may have a richer theoretical knowledge of education, lacking practical teaching experience and understanding of the students, they are not capable of up to the teaching standards of the backbone teachers in a short period. And the negative impact of these on teaching effectiveness can't be ignored. Therefore, the single training mode at present can't reflect the professional development needs of different teachers.

In light of the above, the author believes that the following aspects should be paid attention to during the implementation of the National Education Program: In terms of curriculum setting, it is necessary to take into account the updating of educational and teaching theories as well as the weak basic knowledge of a considerable number of teachers, to continue to improve their basic skills in their major; In terms of training mode, pertinence and effectiveness should be enhanced, and theories should be 
closely integrated with practice.

\section{Effective Training Approaches}

1) Selection of training teachers

Transferring "require me to train" to "I want to train", which means selecting strictly in the process of choosing trained teachers. It can change the phenomenon that teachers' training has an inevitable relationship with the evaluation of the title-promotion. Specific implementation can be carried out by questionnaire survey before the training, selecting the teachers who hope to improve the level of educational theory and teaching ability, and training the teachers who have the highest desire to participate in the training. These teachers have a high demand for the sense of achievement from the profession itself, so they have high enthusiasm and initiative to participate in training. And they will also participate in training with problems they found in work. When listening to theoretical knowledge by experts, these teachers will think critically, communicate with experts and other teachers actively and understand the new curriculum knowledge better, which promotes the transformation of theory to practice.

\section{2)Setting of training content}

When formulating the content of the teachers' continuing education and training, we should proceed from the practice and combine the content of compulsory education curriculum effectively, including curriculum standard and teaching design of compulsory education stage, teaching theory, teaching method, cultivating and guidance of students' self-study ability and learning environment and teaching resources. Only in this way can we make up for the deficiencies in the specific training and teach students according to their own needs, which can achieve the autonomy, pertinence, and effectiveness of continuing education.

Taking the junior middle school English teacher training as an example, the setting of training content should include the following aspects. Let trained teachers understand how to organically combine every aspect involved in the curriculum standards which contains teaching ideas, methods, and steps in the teaching of a unit. Let them know how to make use of the surrounding teaching resources and create an English learning environment during teaching. And they should learn how to evaluate students in the teaching process and even select teaching aids, the blackboard design, and reflection. They also should observe in other teachers' classes to learn how to observe from some aspects or perspectives and what to do after observation.

3)With the carrier of "internship on the post and replacement training", carry out cooperation and promote the development of teacher education

As a major activity in the "Backbone Teacher Training Project in Central and Western Rural Areas", the "Internship and Replacement Training" project allows senior normal students from training colleges to go to the rural primary and secondary schools where the training teachers are dispatched for internships, and at the same time replace local teachers. School teachers leave their posts to receive training in colleges and universities. During the training period, colleges and universities bring 
the trained teachers to the training base school to observe and discuss research. This project can not only encourage teachers to effectively improve their professional knowledge but also truly enable them to apply the theoretical knowledge they have learned to teach practice, to achieve a genuinely "integration of teaching, learning and doing". Therefore, to achieve the long-term effect of training, we need to advocate the use of "internship on the post, replacement training" as the carrier to carry out cooperation between higher normal colleges and local basic education institutions, elementary and secondary education bases to promote the integrated training of in-service teachers and pre-service teachers education development model. Integrating the members of the "Teacher Education Cooperation Community" closely to achieve real cooperation among universities, primary and secondary schools, will provide each other's needs and make it up for each other. Only in this way can the "Teacher Education Cooperation Community" be consolidated and developed in the work, and truly promote the development of teacher education.

Meanwhile, an implementation of the overall allocation of urban and rural English teacher training resources, with the centralized training of college teachers and the training of sending teachers to the countryside, and the training of sending teachers to urban primary and secondary schools to observe and study, it can promote the release of functions in training resource and effective use.

\section{Conclusion}

The problems in the training process listed above are no exception, but are common phenomena in the entire "National Training Program". If you let it go without thinking about improvement, it will deviate from the original track of "National Training". Ultimately, it will affect the effectiveness of teacher training. Therefore, to enhance the pertinence and effectiveness of English teacher training in rural primary and secondary schools, and to promote primary education reform, we must improve the training model. From the selection of trained teachers and the setting of training content to the teacher education cooperative community based on "internship and replacement training", we should regard teacher training as a continuous and organic process and implement pre-service cultivation and post-work training to improve the overall quality of in-service teachers step by step.

\section{References}

[1]. Ministry of Education. Opinions of the Ministry of Education on vigorously promoting the work of teaching internships for normal students[S]. Teacher (2007) No. 4, 2007-07-05.

[2]. Su Xing. Gain and loss in the replacement training of teachers-based on the survey and interviews of replacement teachers in the internship replacement training project of Hubei University[J]. Journal of Southeast University (Philosophy and Social Sciences Edition), 2011, (6).

[3]. Zhang Erqing, Wang Xiuhong. The main problems existing in teacher training in our country and their analysis. A case study of "National Training Program"[J]. Journal of Educational Science of Hunan Normal University, 2012, (7). 
[4]. He Hongcui. The Tian Jiabing Foundation helps poor areas in Chongqing (the stage, content and characteristics of junior high school English teacher training[J]. Teacher training, 2012, (5)

[5]. Huang Jiaqing.The conception of teacher education model innovation and enlightenment from internship replacement training $[\mathrm{J}]$. Higher Education Forum, 2010, (4).

[6]. FuShujing. University and Primary and Secondary School Cooperative Development: Concept and Practice [J]. Liaoning Educational Research, 2003, (5). 